\title{
Retrieval of the photochemical reflectance index for assessing xanthophyll cycle activity: a comparison of near-surface optical sensors
}

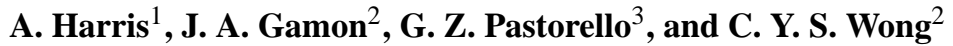 \\ ${ }^{1}$ Geography, School of Environment, Education and Development, University of Manchester, \\ Manchester, M13 9PL, UK \\ ${ }^{2}$ Departments of Earth \& Atmospheric Sciences and Biological Sciences, University of Alberta, \\ Edmonton, AB T6G 2E3, Canada \\ ${ }^{3}$ Computational Research Division, Lawrence Berkeley National Laboratory, CA 94720, USA
}

Correspondence to: A. Harris (angela.harris@manchester.ac.uk)

Received: 9 June 2014 - Published in Biogeosciences Discuss.: 6 August 2014

Revised: 9 October 2014 - Accepted: 16 October 2014 - Published: 21 November 2014

\begin{abstract}
Unattended optical sensors are increasingly being deployed on eddy covariance flux towers and are often used to complement existing vegetation and micrometeorological measurements to enable assessment of biophysical states and biogeochemical processes over a range of spatial scales. Of particular interest are sensors that can measure the photochemical reflectance index (PRI), which can provide information pertaining to leaf pigments and photosynthetic activity. This interest has facilitated the production of a new range of lower-cost multispectral sensors specifically designed to measure temporal changes in the PRI signal. However, little is known about the characteristics (spectral, radiometric and temporal) of many of these PRI sensors, making it difficult to compare data obtained from these sensors across time, geographical locations and instruments. Furthermore, direct testing of the capability of these sensors to actually detect the conversion of the xanthophyll cycle, which is the original biological basis of the PRI diurnal signal, is largely absent, often resulting in an unclear interpretation of the signal, particularly given the wide range of factors now known to influence PRI. Through a series of experiments, we assess the sensitivity of one of the leading brands of PRI sensor (Skye SKR 1800) to changes in vegetation photosynthetic activity in response to changing irradiance. We compare the results with those obtained using a more expensive industry-standard visible to near-infrared hyperspectral spectrometer (PP Systems UniSpec) and determine the radiomet-
\end{abstract}

ric compatibility of measurements made by the different instruments. Results suggest that the SKR 1800 instrument is able to track rapid (seconds to minutes) and more gradual diurnal changes in photosynthetic activity associated with xanthophyll cycle pigment conversion. Measurements obtained from both the high and lower cost instrument were significantly linearly correlated but were subject to a large systematic bias, illustrating that differences in instrument configuration (e.g. spectral response functions and band positions) can have a large impact on the PRI measurement values obtained. Despite differences in absolute PRI values, significant correlations were observed between the canopy PRI derived from both the SKR 1800 and the UniSpec instruments, and the epoxidation state of the xanthophyll cycle $\left(r^{2}=0.46\right.$ $p<0.05$ and $r^{2}=0.76 p<0.01$, respectively). However, the dynamic range of the SKR 1800 PRI signal was often lower than more expensive instruments and thus the lower cost multispectral instrument may be less sensitive to pigment dynamics related to photosynthetic activity. Based on our findings, we make a series of recommendations for the effective use of such sensors under field conditions and advocate that sensors should be fully characterized prior to their field deployment. 


\section{Introduction}

Quantitative estimates of carbon dioxide exchange at regional to global scales are critical for understanding the links between carbon and climate. Eddy covariance (EC) flux tower measurements are the key means of providing direct measures of trace gas and water fluxes between the biosphere and the atmosphere. Whilst EC methods are of great importance for carbon balance estimations (Baldocchi et al., 2001), the measurements are often only representative of a limited geographical region directly surrounding the flux tower and their number and distribution across the globe is limited and uneven. Remote sensing can provide spatially continuous data across a range of spatial scales and is rapidly becoming an important supplementary source of information for carbon monitoring and modelling efforts (e.g. Liu et al., 1999; Turner et al., 2003; Reichstein et al., 2007; Jung et al., 2011). Through the use of satellites such as MODIS (Moderate Resolution Imaging Spectrometer), remote sensing can be used to derive regional and global measures of vegetation parameters (e.g. leaf area index (LAI) and fraction of absorbed photosynthetically active radiation, $\left(F_{\text {APAR }}\right)$; Myneni et al., 1997), which can be utilized in biogeochemical models for estimating carbon exchange variables such as gross primary productivity (GPP; Running et al., 2004). However, the growing availability of satellites with high spatial and/or spectral resolutions (e.g. Hyperion, Worldview-2, VIIRS and the forthcoming Sentinel-2 satellites), has resulted in an increasing number of investigations aimed at providing quantitative information on the biophysical and chemical functions of vegetation (e.g. Gitelson et al., 2005; Cheng et al., 2010; Harris and Dash, 2010; Huemmrich et al., 2010; Garbulsky et al., 2011; Hilker et al., 2011) potentially providing a new source of data for existing or new productivity models (Hill et al., 2006). Spectral vegetation indices, based on reflected radiation, which have the potential to track changes in the light use efficiency (LUE) of vegetation (Monteith and Moss, 1977), such as the photochemical reflectance index (PRI), are of particular interest. Specifically, the PRI was formulated to measure changes in reflectance at $\sim 531 \mathrm{~nm}$ on a diurnal timescale, which are related to the state of epoxidation of the xanthophyll cycle pigments caused by excess light energy (Gamon et al., 1990, 1992, 1993). Because of the relationship between excess light and photosystem II (PSII) photochemical efficiency, the PRI can also provide an estimate of photosynthetic light-use efficiency (Gamon et al., 1992; Peñuelas et al., 1995).

Validation and correct interpretation of remotely sensed data is essential if they are to be used to facilitate an improved understanding of global carbon fluxes (Gamon et al., 2006b). Near-surface spectral measurements can provide a detailed characterization of the Earth's surface and minimize or eliminate exogenous influences (e.g. atmospheric conditions, changes in illumination and geometry, and calibration drift) on the reflectance signal, which are often apparent in airborne and satellite measurements. As a consequence, nearsurface optical measurements play an important role not only in the calibration and validation of airborne and satellite data (Smith and Milton, 1999; Gamon et al., 2006b; Milton et al., 2009; Wright et al., 2014), but also in their mechanistic interpretation and use for scaling carbon flux estimations (Williams et al., 2008; Stoy et al., 2013).

The recent proliferation of interest in near-surface spectral data for carbon flux modelling, coupled with a lowering in the cost of unattended optical instruments, is such that these instruments are increasingly being deployed for long term in situ temporal monitoring, many of which are mounted on eddy covariance flux towers (Eklundh et al., 2011; Rossini et al., 2012; Soudani et al., 2012; Hilker et al., 2011; Hmimina et al., 2013). However, the comparability and reproducibility of the spectral data between monitoring sites is often compromised because of differences in instrument configurations (e.g. differences in internal optics, spectral wavelengths and bandwidths) and deployment (e.g. distance from the ground and angle of measurement; Milton et al., 2009; Anderson et al., 2013; Pacheco-Labrador and Martin, 2014). In response, international networks such as SpecNet (http://www.specnet.info; Gamon et al., 2006b) and Cost Action ES0903-EUROSPEC (http://cost-es0903. fem-environment.eu/) have been formed to help standardize and develop optical sampling methodologies. However, there are comparatively few studies that have investigated the comparability and reproducibility of near-surface optical measurements (e.g. Anderson et al., 2013; Castro-Esau et al., 2006; Pacheco-Labrador and Martin, 2014), and few that have focused on the comparability of data obtained from lower cost instruments specifically developed for unattended field deployment (e.g. Fitzgerald, 2010; Eklundh et al., 2011; Erdle et al., 2011; Yao et al., 2013). Most of these focus on characterizing instruments designed to measure broadband spectral indices such as the normalized difference vegetation index (NDVI) whereas comparisons of automated sensors designed to collect fine spectral resolution multispectral data, such as those used to measure the narrowbands required to calculate the PRI, are sorely lacking. The narrowband nature of the PRI is such that the index is likely to be highly sensitive to between-sensor differences in spectral bandwidths and locations of the spectral bands (Castro-Esau et al., 2006). The potential of narrowband indices, such as the PRI, for monitoring carbon relevant physiological changes in vegetation is such that cross-sensor comparison studies of these types of instruments are essential if these data are to be effectively utilized by the scientific community.

This paper reports the results of a series of comparative experiments aimed at assessing both the sensitivity of nearsurface optical instruments to changes in vegetation photosynthetic activity and the radiometric compatibility of PRI measurements from instruments that differ in their spectral configuration and cost (PP Systems UniSpec and Skye SKR 1800), with the goal of recommending a strategy for their 
Table 1. Principal characteristics of the optical instruments used.

\begin{tabular}{lccccc}
\hline $\begin{array}{l}\text { Instrument } \\
\text { name }\end{array}$ & $\begin{array}{c}\text { Wavelength } \\
\text { range }(\mathrm{nm})\end{array}$ & $\begin{array}{c}\text { FWHM } \\
(\mathrm{nm})\end{array}$ & $\begin{array}{c}\text { Sampling } \\
\text { interval }(\mathrm{nm})\end{array}$ & $\begin{array}{c}\text { Downward } \\
\text { FOV }\left({ }^{\circ}\right)\end{array}$ & $\begin{array}{c}\text { Operating temperature } \\
\text { range }\left({ }^{\circ} \mathrm{C}\right)\end{array}$ \\
\hline $\begin{array}{l}\text { PP Systems UniSpec } \\
\text { Dual Channel (DC) }\end{array}$ & $310-1100$ & 10 & 3.3 & $20^{\mathrm{a}}$ & $0-50$ \\
\hline PP Systems UniSpec & $310-1100$ & 10 & 3.3 & $20^{\mathrm{a}}$ & $0-50$ \\
Single Channel (SC) & & & & & \\
\hline Skye SKR 1800 & & & & NA & -25 to $+25^{\mathrm{c}}$ \\
$\quad$ Upward sensor & 531 & 7.0 & NA & NA & -25 to $+25^{\mathrm{c}}$ \\
& 567 & 6.3 & NA & 25 to $+25^{\mathrm{c}}$ \\
\multicolumn{1}{c}{ Downward sensor } & 530 & 6.1 & NA & $25^{\mathrm{b}}$ & -25 to $+25^{\mathrm{c}}$ \\
\hline
\end{tabular}

a These values refer to the manufacturer's nominal FOV for the UniSpec using a fibre optic fitted with a FOV restrictor (Hypo-Tube, PP Systems, Amesbury, MA, USA), although preliminary user tests suggest the actual FOV is closer to $15^{\circ} ;{ }^{\mathrm{b}} 12.5^{\circ}$ off perpendicular; ${ }^{\mathrm{c}}$ manufacturer's values for a fixed PVC cable.

effective use. We present results from a series of shaderemoval and diurnal experiments designed to test each instrument's capability for detecting rapid (seconds to minutes) changes in the epoxidation state of the xanthophyll cycle under clear and stable lighting conditions, and more gradual changes in photosynthetic activity in response to diurnal changes in illumination. We further assessed the quality of the PRI measurements by comparing them with leaf-level measurements and pigments, to determine whether canopy PRI measurements from each sensor are related to changes in the xanthophyll cycle or an artefact of other nonphysiological processes. We also investigated the impacts of differences in the spectral response function and working principles of individual instruments, by means of measurement inter-comparisons, in which magnitudes of systematic differences between the sensors and vegetation canopy dependencies were examined.

\section{Methods}

\subsection{Instruments}

Performance comparisons were assessed using a pool of 3 different instruments (Table 1). The instruments were chosen to facilitate a comparison of the results obtained from a commonly used commercially available lower-cost two-band sensor specifically designed for field deployment and continuous in situ monitoring, with those obtained from more expensive hyperspectral industry-standard instruments that are field-portable but not specifically designed to be deployed unattended in the field without further hardening (e.g. Hilker et al., 2011). Towards this aim, over the duration of the study, we used three industry-standard UniSpec spectroradiometers (PP Systems, USA), which are capable of measuring reflectance throughout the visible to near-infrared regions (VIS-NIR) of the electromagnetic spectrum at $\sim 3 \mathrm{~nm}$ sam- pling intervals, and a pair of SKR 1800 sensors (Skye Instruments, UK), which incorporate just two narrow green wavebands for computation of the PRI, the exact wavelengths of which depend on the manufacturer's filter selection and calibration (see Sect. 2.2).

UniSpec instruments are available in both a single channel (SC) and dual channel (DC) configuration. The DC instrument was used to facilitate the collection of rapid continuous reflectance measurements during dark-to-light experiments, whereas the two SC instruments were used to obtain near simultaneous canopy and leaf-level reflectance measurements during the diurnal experiment. When using the SC configuration, measurements of the solar radiance (often obtained from measuring the reflectance of a highly reflective Lambertian white panel) and the reflectance from the target are obtained sequentially; whereas the DC configuration measures solar irradiance and target reflectance simultaneously (often by means of an additional upward looking sensor head fitted with a cosine diffuser), thereby minimizing the impact of changes in the atmosphere on reflectance measurements (Rollin et al., 1998) and facilitating automation. To calculate reflectance, the DC instrument requires a cross-calibration between the upward- and downward-looking sensors (Gamon et al., 2006a). The SKR 1800 sensors operate in a similar configuration to the DC instrument; consisting of a pair of sensors where one looks downward towards the target and the other is equipped with a cosine correction diffuser and points upwards to measure hemispherical irradiance. The first generation SKR 1800 sensors use relative calibration factors of two detectors on the same sensor to generate the PRI. Following the manufacturer's guidelines, these sensors can only calculate ratio-based indices and not reflectance values. Although not part of the manufacturer's recommendations, a user level in situ cross-calibration between the upward and downward SKR 1800 sensors can be undertaken to allow the user to retrieve reflectance values for individual spectral 
bands (see Sect. 2.2). Furthermore, this type of user-level cross-calibration can be used to provide a relative calibration for the sensors if the manufacturer's calibration certificate has expired and to check the stability of sensor calibrations over time (Jin and Eklundh, 2013).

\subsection{Processing of spectral data}

The photochemical reflectance index (PRI) was calculated from data obtained by each of the different instruments. The means by which the PRI values were obtained differed depending on the instrument configuration but the formulation of the PRI equation remained the same throughout (Eq. 1).

$\mathrm{PRI}=\frac{R_{531 \mathrm{~nm}}-R_{570 \mathrm{~nm}}}{R_{531 \mathrm{~nm}}+R_{570 \mathrm{~nm}}}$,

where $R_{531} \mathrm{~nm}$ and $R_{570} \mathrm{~nm}$ refer to the reflectance factors at 531 and $570 \mathrm{~nm}$, respectively. We refer to $531 \mathrm{~nm}$ and $570 \mathrm{~nm}$ as the PRI wavelengths for the UniSpec and SKR 1800 instruments in subsequent equations, although slight differences in the PRI wavelengths for the SKR 1800 should be noted (Table 1).

\subsubsection{UniSpec dual channel (DC) instrument}

The UniSpec DC instrument was operated in cosine-conical mode where downwelling and upwelling radiation are sampled simultaneously. To account for potential differences in sensor properties between the upward and downward sensor channels, measures of a white reference panel (Spectralon, LabSphere, North Sutton, NH, USA) were made at the start and end of each experiment to provide a crosscalibration function, which was used to calculate the hemispherical-conical reflectance factor (HCRF) using Eq. (2) (Gamon et al., 2006a).

$R_{\text {corrected }}=\frac{R_{\text {target }} / I_{\text {downwelling }}}{R_{\text {panel }} / I_{\text {downwelling }}}$,

where $R_{\text {corrected }}$ is the corrected reflectance factor and $R_{\text {target }} / I_{\text {downwelling }}$ is the raw reflectance factor and $R_{\text {panel }} / I_{\text {downwelling }}$ is the cross-calibration function.

\subsubsection{UniSpec single channel (SC) instrument}

Canopy HCRFs were measured by the UniSpec SC using periodic measurements taken from the horizontal white reference panel using Eq. (3):

$R_{\text {corrected }}=\frac{R_{\text {target }}}{R_{\text {panel }}}$,

where $R_{\text {corrected }}$ is the corrected reflectance factor, $R_{\text {target }}$ is the radiance from the target and $R_{\text {panel }}$ is the radiance from the white reference panel. PRI was calculated from the reflectance spectrum using Eq. (1)
Leaf-level spectral measurements were made using the UniSpec SC attached to a leaf clip with an integrated illumination source, which enabled repeatable sampling of radiance at a fixed geometry and under identical illumination conditions (Gamon and Surfus, 1999). Each set of measurements was preceded by the measurement of a white Spectralon reference disc and the leaf-level HCRF was obtained using Eq. (3).

\subsubsection{SKR 1800 sensors}

The SKR 1800 upward-looking cosine sensor $\left(180^{\circ}\right.$ FOV, field of view) was calibrated to irradiance $\left(\mu \mathrm{mol} \mathrm{m}{ }^{-2} \mathrm{~s}^{-1} \mu \mathrm{A}^{-1}\right)$ by the manufacturer, however for first generation sensors such as those used in this study, the downward sensor did not have an absolute calibration. Consequently, the HCRF at individual wavelengths cannot be obtained directly although the PRI can be calculated from the relative sensitivity of the two wavelength channels in the same sensor. The PRI was calculated following the manufacturer's guidance using Eq. (4):

$\mathrm{PRI}=\frac{\left(R_{531 \mathrm{~nm}} / I_{531} \mathrm{~nm}\right)-\left(Z \times R_{570 \mathrm{~nm}} / I_{570 \mathrm{~nm}}\right)}{\left(R_{531 \mathrm{~nm}} / I_{531} \mathrm{~nm}\right)+\left(Z \times R_{570 \mathrm{~nm}} / I_{570 \mathrm{~nm}}\right)}$,

where $Z$ is the ratio sensitivity of reflected $570: 531 \mathrm{~nm}$ light, $R_{531 \mathrm{~nm}}$ and $R_{570 \mathrm{~nm}}$ are the reflected readings at $531 \mathrm{~nm}$ and

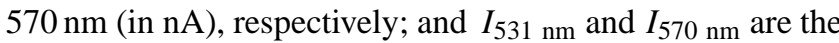
incident $\left(\mu \mathrm{mol} \mathrm{m}{ }^{-2} \mathrm{~s}^{-1} \mu \mathrm{A}^{-1}\right)$ readings for 531 and $570 \mathrm{~nm}$, respectively.

An in situ relative cross-calibration was also used to calculate the HCRF for each of the SKR 1800 wavelength channels (i.e. 531 and $570 \mathrm{~nm}$ ) for the diurnal experiment. At regular intervals throughout the day, a white reference panel was positioned underneath the downward facing SKR 1800 sensor. A robust linear regression was subsequently performed on the white panel data to determine the relative sensitivity of the upward and downward facing sensors, for each wavelength channel. The resultant coefficients were used to normalize the raw data (nA) using Eq. (5) prior to calculating the HCRF for each wavelength channel.

Reflectance $_{x}=\frac{R_{x}}{m I_{x}+c}$,

where Reflectance $e_{x}$ is the reflectance factor at a given wavelength (i.e. $531 \mathrm{~nm}$ or $570 \mathrm{~nm}$ ), $R_{x}$ and $I_{x}$ are the raw readings (nA) from the downward and upward looking sensors (respectively) for wavelength channel $x$, and $m$ and $c$ are the coefficients derived from the white panel measurements. Robust linear regression was implemented in the $\mathrm{R}$ statistical environment (R Development Core Team, 2012) using the MASS package (Venables and Ripley, 2002). 
Table 2. Summary of types of experiment undertaken by species, including the sensors that were used and whether spectral data were collected at the canopy level or leaf level.

\begin{tabular}{|c|c|c|c|c|c|}
\hline Species & $\begin{array}{l}\text { Type of } \\
\text { experiment }\end{array}$ & Scale & $\begin{array}{l}\text { Instruments } \\
\text { used }\end{array}$ & $\begin{array}{l}\text { Additional } \\
\text { data }\end{array}$ & $\begin{array}{l}\text { Date and } \\
\text { time (LT) }\end{array}$ \\
\hline $\begin{array}{l}\text { Alfalfa } \\
\text { (Medicago sativa) }\end{array}$ & Dark-to-light & Canopy & $\begin{array}{l}\text { UniSpec DC; } \\
\text { SKR } 1800\end{array}$ & $\begin{array}{l}\text { PPFD; } \\
\text { temperature }\end{array}$ & $\begin{array}{l}26 \text { Jul } 2012 \\
13: 30-14: 00\end{array}$ \\
\hline $\begin{array}{l}\text { Aspen } \\
\text { (Populus tremuloides) }\end{array}$ & Dark-to-light & Canopy & $\begin{array}{l}\text { UniSpec DC; } \\
\text { SKR } 1800\end{array}$ & $\begin{array}{l}\text { PPFD; } \\
\text { temperature }\end{array}$ & $\begin{array}{l}3 \text { Aug } 2012 \\
14: 00-15: 00\end{array}$ \\
\hline $\begin{array}{l}\text { Ponderosa Pine } \\
(\text { Pinus ponderosa) }\end{array}$ & Dark-to-light & Canopy & $\begin{array}{l}\text { UniSpec DC; } \\
\text { SKR } 1800\end{array}$ & $\begin{array}{l}\text { PPFD; } \\
\text { temperature }\end{array}$ & $\begin{array}{l}28 \text { Jun } 2013 \\
14: 20-14: 40\end{array}$ \\
\hline $\begin{array}{l}\text { Strawberry } \\
(\text { Fragaria } x \text { ananassa) }\end{array}$ & Dark-to-light & Canopy & $\begin{array}{l}\text { UniSpec DC; } \\
\text { SKR } 1800\end{array}$ & $\begin{array}{l}\text { PPFD; } \\
\text { temperature }\end{array}$ & $\begin{array}{l}28 \text { Jun } 2013 \\
13: 20-13: 50\end{array}$ \\
\hline $\begin{array}{l}\text { Lodgepole pine } \\
\text { (Pinus contorta) }\end{array}$ & Diurnal & $\begin{array}{l}\text { Canopy } \\
\text { and leaf }\end{array}$ & $\begin{array}{l}\text { UniSpec SC; } \\
\text { SKR } 1800\end{array}$ & $\begin{array}{l}\text { PPFD; } \\
\text { temperature; } \\
\text { xanthophyll } \\
\text { pigments }\end{array}$ & $\begin{array}{l}25 \text { Jul } 2013 \\
06: 30-19: 50\end{array}$ \\
\hline
\end{tabular}

\subsubsection{Correcting for differences in instrument spectral response function}

The UniSpec instruments and each of the SKR 1800 sensors have different spectral response functions (SRFs) (e.g. band centres and full width at half maximum; FWHM), which result in differences between instruments in the PRI wavelengths (Fig. 1). The spectral resolution (defined as the FWHM) of the UniSpec instruments is approximately $10 \mathrm{~nm}$ with a $\sim 3 \mathrm{~nm}$ sampling interval. The data are subsequently interpolated to $1 \mathrm{~nm}$ intervals during processing and the $\mathrm{HCRF}$ at 531 and $570 \mathrm{~nm}$ is used for the calculation of PRI in both the SC and DC configurations. For the SKR 1800 sensors the PRI wavelengths are centred at 530 and $569 \mathrm{~nm}$ for the reflected radiation (i.e. the downward facing sensor) and 531 and $567 \mathrm{~nm}$ for the upward looking sensor recording incoming irradiance. As noted above, these values are a function of the particular filters chosen by the manufacturer and can vary from one batch of sensors to the next. To understand how instrument SRFs may influence the PRI, we convolved the UniSpec spectra with the manufacturer supplied SRFs for the SKR 1800 downward-facing sensors and compared SKR 1800 PRI values to those obtained from the UniSpec before and after spectral convolution. As the SKR 1800 sensor only contains two wavebands we used the UniSpec $(1 \mathrm{~nm}$ spectral data) to simulate each of the bands separately using the method outlined by Robinson and MacArthur (2011) so that the output value for each band is the integral of the product of the SKR 1800 SRF and the UniSpec input spectrum. All calculations were implemented in the $R$ statistical environment.

\subsection{Experimental set-up}

All experiments were performed at the University of Alberta campus, Edmonton, Canada during July and August 2012 and 2013. Two types of experiment were undertaken during this period: (i) a series of midday shade removal studies, which provided an abrupt transition from low to high light intensities over a range of plant canopies; and (ii) a single diurnal study that followed PRI change under ambient sunlight. Both types of experiment were designed to observe the canopies as they underwent physiological transitions from their dark state to full illumination, and facilitated an investigation of the sensitivity of the different instruments to changes in vegetation photosynthetic activity and the radiometric compatibility of the PRI measurements. A series of custom sensor mounts were designed to ensure that on each occasion all instruments used for inter-comparisons were viewing as similar a portion of the plant canopy as was physically possible. The area viewed by each instrument was approx. $20 \mathrm{~cm}$ in diameter. Similar experimental protocols were applied to all sets of measurements collected.

\subsubsection{Experiment 1: dark-to-light transitions}

Dark-to-light transition experiments were performed over four different plant canopies (Table 2) following a similar approach to that described in Gamon et al. (1990). Strawberry (Fragaria $\times$ ananassa), ponderosa pine (Pinus ponderosa) and trembling aspen (Populus tremuloides) were all grown on the roof of the Biological Sciences building, University of Alberta. The strawberry plants were cultivated in a large $(2 \times 2 \mathrm{~m})$ flat crate. The pine and aspen saplings were approximately 4 and 3 years old, and around 1 and $1.5 \mathrm{~m}$ in height, respectively. Both species were grown in large pots $(6.23 \mathrm{~L})$ using a $1: 2 \mathrm{mix}$ of sandy loam and 


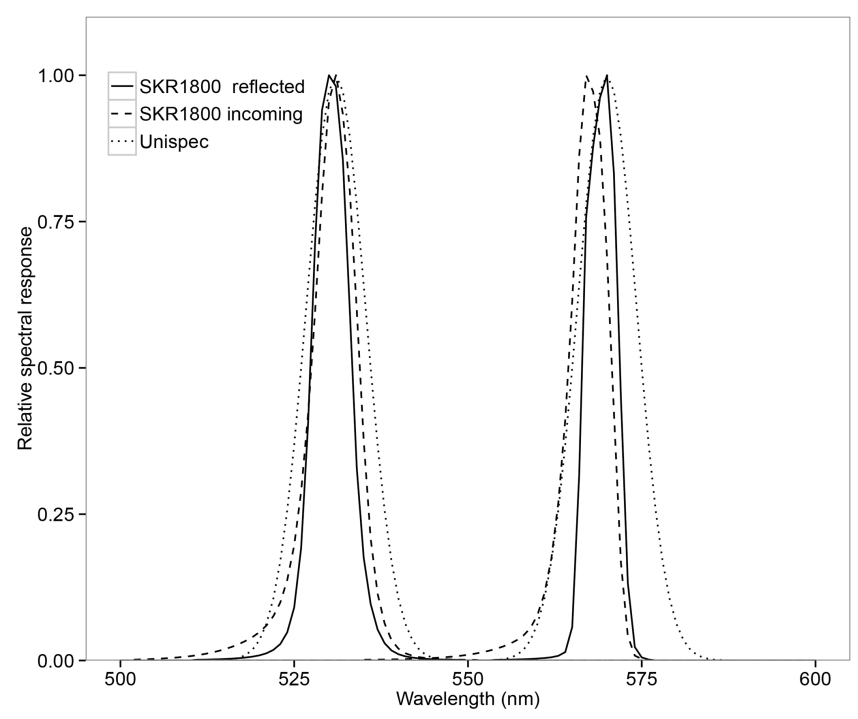

Figure 1. Spectral response curves for the UniSpec instruments and the upward- (incoming) and downward-looking (reflected) SKR 1800 sensor pair.

commercial potting soil (Sunshine Mix 4, Sun Gro Horticulture, Agawam, MA, USA) supplemented with slow release fertilizer (Nutricote 14-14-14, Sun Gro Horticulture, Agawam, MA, USA), and arranged in a wooden crate $(1 \times 1 \mathrm{~m})$ to simulate a dense seedling monoculture stand. The alfalfa (Medicago sativa) was grown as a perennial crop on the university South Campus farm (Edmonton, Alberta) and was approximately $0.4 \mathrm{~m}$ high at the time measurements were collected. With the exception of the alfalfa, all plants were irrigated and fertilized regularly. The alfalfa received no supplemental fertilizer or irrigation.

On each sampling occasion plants were covered with a black shade cloth the evening prior to the experimental measurements. Near solar noon the following day, the shade cloth was abruptly removed, exposing the plants to full sunlight. The rapid response of plants to excess photosynthetic photon flux density (PPFD) was such that changes in sun angle, canopy structure and leaf movement, which can confound PRI measurements, had limited influence on the spectral measurements (Gamon et al., 1990, 1992). Over the next $\sim 30$ min, canopy HCRF was collected from multiple instruments (Table 2 ) at $\sim 10 \mathrm{~s}$ intervals over the previously shaded plant canopy. The PRI from the UniSpec DC was obtained using Eqs. (1) and (2) whereas the PRI from the SKR 1800 sensors was derived from Eq. (4) (see Sect. 2.2 for equations and details of spectral processing).

Time series plots were used to visually examine dynamic changes in the canopy PRI. The mean difference (MD) between the values of PRI derived from the SKR 1800 and UniSpec DC instruments, along with the standard deviation of the differences (SD) and of the mean difference (or standard error, SE) were computed as a quantitative measure of discrepancies:

$\mathrm{MD}=\frac{1}{n} \sum_{i=1}^{n}\left(x_{i}\right.$, SKR $1800-x_{i}$, Unispec DC $)$

$\mathrm{SD}=\sqrt{\frac{1}{n-1} \sum_{i=1}^{n}\left[x_{i}, \text { SKR } 1800-x_{i}, \text { UniSpec DC }-\mathrm{MD}\right]^{2}}$

$\mathrm{SE}=\frac{\mathrm{SD}}{\sqrt{n}}$,

where $x_{i}$,SKR 1800 and $x_{i}$, UniSpec DC are the PRI values of SKR 1800 and UniSpec DC instruments, respectively. The same comparative analysis was repeated for pooled data and data stratified by species.

\subsubsection{Experiment 2: a diurnal study}

A diurnal experiment was undertaken to explore the relationships between PRI measurements and the epoxidation state of the xanthophyll cycle pigments under naturally changing sunlight. The influence of changing sun angle and low light levels on measured PRI and diurnal dependencies of sensor differences were also assessed. Measurements were collected from 06:30 LT to 19:50 LT on 25 July 2013 over a potted lodgepole pine (Pinus contorta) closed-canopy synthetic stand $(1 \times 1 \mathrm{~m}$ plot $)$. The pine saplings were approximately 4 years old, well-watered and located on the roof of the Biological Sciences building at the University of Alberta.

Canopy PRI was measured at $1 \mathrm{~min}$ intervals from the automated SKR 1800 sensors and at $\sim 15$ min intervals for the UniSpec SC instrument. In addition, hourly leaf-level HCRFs were measured using a separate UniSpec SC instrument fitted with a needle leaf clip, bifurcated fiber optic and an internal light source. On each occasion, leaf spectral measurements were recorded from the same four plants, one located in each of the four corners of the study plot $(n=40)$. Sample leaves were randomly chosen from the top of each plant canopy. Needles with a similar orientation and sun exposure to those used for leaf reflectance factor measurements were also sampled ( 2 needles per plant, each $3 \mathrm{~cm}$ long) and immediately frozen in liquid nitrogen for analysis of xanthophyll cycle pigments using high-performance liquid chromatography (HPLC; 1260 Infinity, Agilent Technologies, Santa Clara, CA, USA) and the procedure of Thayer and Björkman (1990). The epoxidation state (EPS) was calculated from the area-based molar concentrations of the three xanthophyll cycle pigments, violaxanthin $(V)$, antheraxanthin $(A)$, and zeaxanthin $(Z)$ using Eq. (9):

$\mathrm{EPS}=\frac{[V]+0.5[A]}{[V]+[A]+[Z]}$.

Incident PPFD was recorded throughout the experiment with a quantum sensor (LI190SB, LI-COR, Lincoln NE, USA). Time series were used to visually examine relationships between PRI and the epoxidation state of the pine canopy as a 
function of illumination conditions, and regression relationships were formulated between PRI and EPS.

\section{Results}

\subsection{Experiment 1: dark-to-light transitions}

\subsubsection{Sensor comparisons}

Figure 2 shows an example of the observed changes in the PRI as an alfalfa canopy was suddenly exposed to high light levels. The dynamic pattern of the PRI was similar for both instruments, although the actual values of the index measured by the SKR 1800 sensors were much higher. When data from all plant canopies used in the dark-to-light experiments were pooled, there was a near-linear relationship between the PRI recorded by both sensors $\left(r^{2}=0.98\right.$; Fig. $\left.3 a\right)$, although the values obtained from the SKR 1800 sensor pair exhibited a lower dynamic range and were consistently and significantly higher $(p<0.0001$, Student's $t$ test) than the UniSpec DC, with a MD of 0.1. After normalizing for instrument configuration differences, using the SRFs for the SKR 1800, the SKR 1800 PRI remained consistently and significantly higher $(p<0.0001$, Student's $t$ test) than those derived from the UniSpec DC, but the values were closer to the $1: 1$ line, and the MD was reduced by a factor of $10(\mathrm{MD}=0.01$, Fig. 3b). Figure 4 summarizes the differences between the two instruments by plant species, after SRF corrections had been applied. Mean PRI instrument differences were similar for alfalfa, aspen and strawberry canopies $(\sim 10-15 \%)$, but SKR 1800 PRI values were often more than twice as high as those measured by the UniSpec DC over the ponderosa pine canopy.

\subsubsection{Tracking physiological change}

The full results of the dark-to-light experiment, after normalizing for different instrument SRFs, can be seen in Fig. 5. For most species, the PRI rapidly decreased upon initial removal of the shade cloth. The largest decreases occurred within the first $5 \mathrm{~min}$ after exposure to sunlight. After the initial reduction, the PRI for aspen and ponderosa pine began to gradually increase as the leaves became acclimatized to the light. The fluctuating nature of the PRI response for aspen can be explained by intermittent cloud cover that was present during the latter part of the experiment (data not shown). Additionally, aspen leaves are prone to fluttering in the wind (Roden and Pearcy, 1992), which may have caused additional fluctuation in the PRI response. Slight differences in the FOV of the two sensors over the aspen canopy may have led to the more evident fluctuations in PRI measured by the UniSpec than measured by the SKR 1800 sensors.

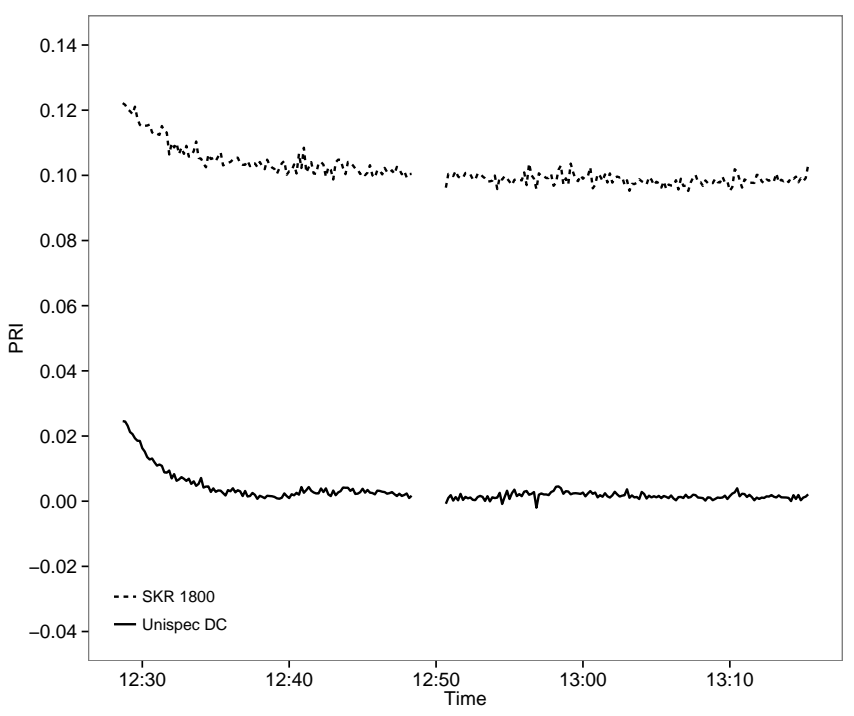

Figure 2. Photochemical reflectance index (PRI) response to a darkto-light transition for alfalfa (Medicago sativa), as recorded by a UniSpec DC instrument and the SKR 1800 sensor pair.

\subsection{Experiment 2: a diurnal study}

Figure 6 illustrates the environmental conditions present during the diurnal experiment undertaken over a lodgepole pine canopy during July 2013. Sky conditions were clear throughout the morning although some clouds were present at noon and became more frequent from 16:00 LT onwards (Fig. 6a). Temperatures throughout the measurement period ranged from $13{ }^{\circ} \mathrm{C}$ at sunrise to a maximum of at $24{ }^{\circ} \mathrm{C}$ at $17: 08 \mathrm{LT}$ (Fig. 6c) whereas relative humidity was highest during the early part of the day $(60-70 \%)$ and lowest during the early to mid-afternoon ( $\sim 5 \%$; Fig. $6 \mathrm{~d})$.

\subsubsection{Sensor comparisons}

Diurnal PRI profiles for the pine canopy (UniSpec SC canopy and SKR 1800) and individual pine needles (UniSpec SC leaf) are shown in Fig. 7a. The PRI was highest in the morning and early evening and lowest during the early to mid-afternoon when both temperature and illumination were greatest (Fig. 6a and c). Leaf-level PRI followed a similar trend to that of the canopy but did not replicate the high values measured at the canopy level during the early part of the day when solar zenith angles (SZAs) were high $\left(\gtrsim 60^{\circ}\right)$. These anomalously high canopy PRI values are unlikely to accurately indicate physiological state. A closer inspection of the full VIS-NIR reflectance spectrum for data collected with the canopy UniSpec instrument illustrated that the observed artefacts at high SZAs were not confined to reflectance factors at 531 and $570 \mathrm{~nm}$ (data not shown), but were probably general responses to high SZAs and low light. When differences in the SRF of each instrument were not taken into account, the SKR 1800 PRI values were significantly higher 

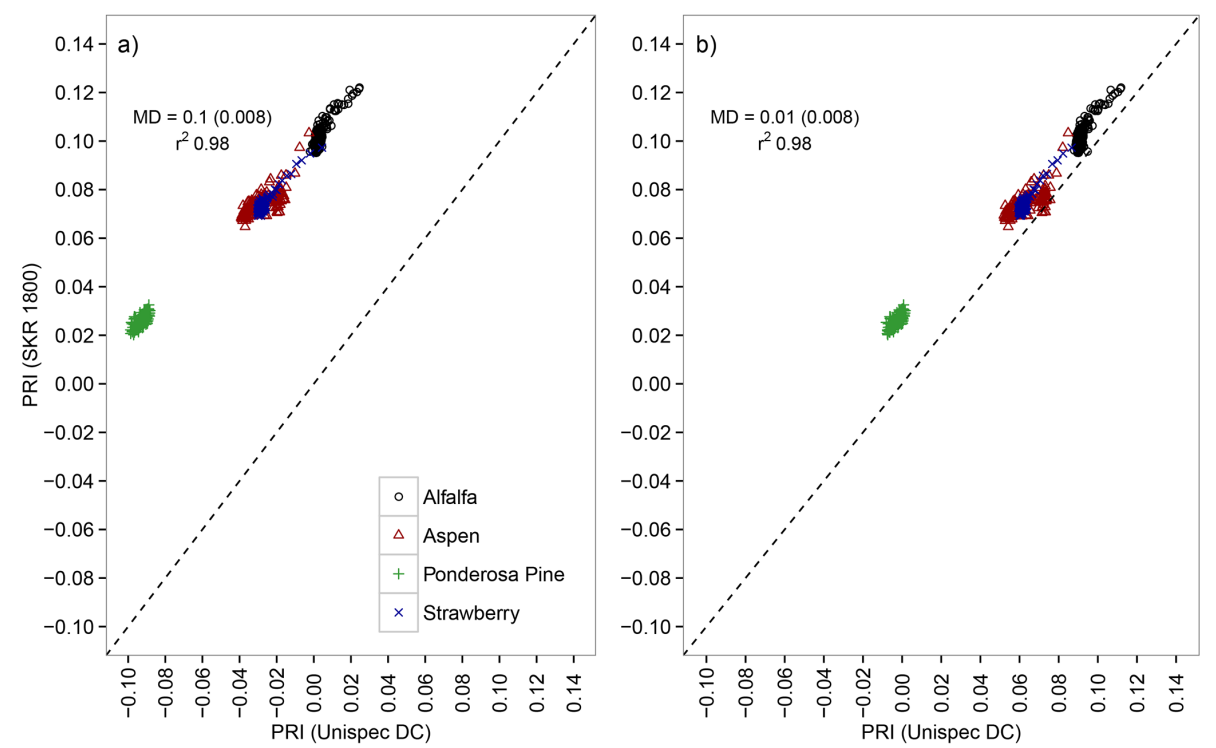

Figure 3. Scatter plots of UniSpec DC photochemical reflectance index (PRI) vs. SKR 1800 PRI across a range of plant canopies during a series of dark-to-light transitions. (a) Depicts the data without correction for differences in SRFs and (b) depicts the data after normalization for differences in the spectral configuration. The dotted lines represent the 1:1 line. MD in the plots stands for mean differences and the values in the parentheses are the standard deviation of the differences.

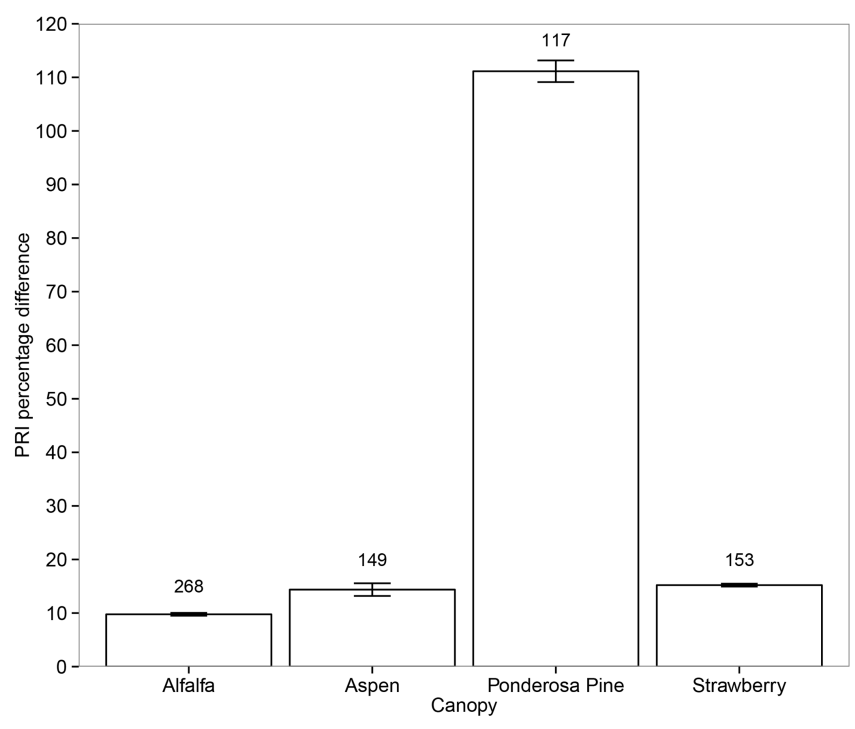

Figure 4. Plant canopy dependencies of UniSpec DC photochemical reflectance index (PRI) vs. SKR 1800 PRI across a range of plant canopies during a series of dark-to-light transitions. Per-canopy mean percentage differences are plotted along with $95 \%$ confidence intervals. The sample sizes (number of pairs) used to compute the mean differences and confidence intervals are given at the tops of the bars. Data shown are those that have been corrected to normalize the SRF differences between instruments.

than those obtained from either of the UniSpec instruments, and the PRI values measured at the leaf level were generally higher than those recorded with the UniSpec instrument over the canopy.

To further investigate the reasons surrounding the comparatively high PRI values derived from the SKR 1800 sensor pair, we used white panel measurements collected throughout the course of the day to perform an in situ crosscalibration of the sensors. The cross-calibration enabled the HCRF to be derived from each of the two SKR 1800 wavelength channels (see Sect. 2.2.3). The diurnal pattern of reflectance factors for the $531 \mathrm{~nm}$ and $570 \mathrm{~nm}$ channels, in comparison to those measured by the UniSpec canopy instrument, are shown in Fig. 8. The figure clearly illustrates differences in the HCRFs measured by each instrument. The $531 \mathrm{~nm}$ reflectance factor recorded by the SKR 1800 sensors is consistently higher than that recorded at $570 \mathrm{~nm}$. However, the opposite is true for both the UniSpec canopy measurements (Fig. 8), and the UniSpec leaf measurements (data not shown). Using Eq. (1) to obtain PRI for these data resulted in a lower PRI for data collected with the UniSpec instruments than those obtained by the SKR 1800 sensors, as shown in Fig. 7a.

Figure $7 b$ compares the diurnal patterns of the PRI from all sensors after the SRF correction had been applied to both UniSpec instruments. The results show that instrument differences observed in the diurnal pattern of the PRI were not purely a consequence of differences in the spectral response. Small differences can be seen between the PRI obtained by the SKR 1800 sensor pair using the manufacturer's calibration and the in situ cross-calibration procedure. These 

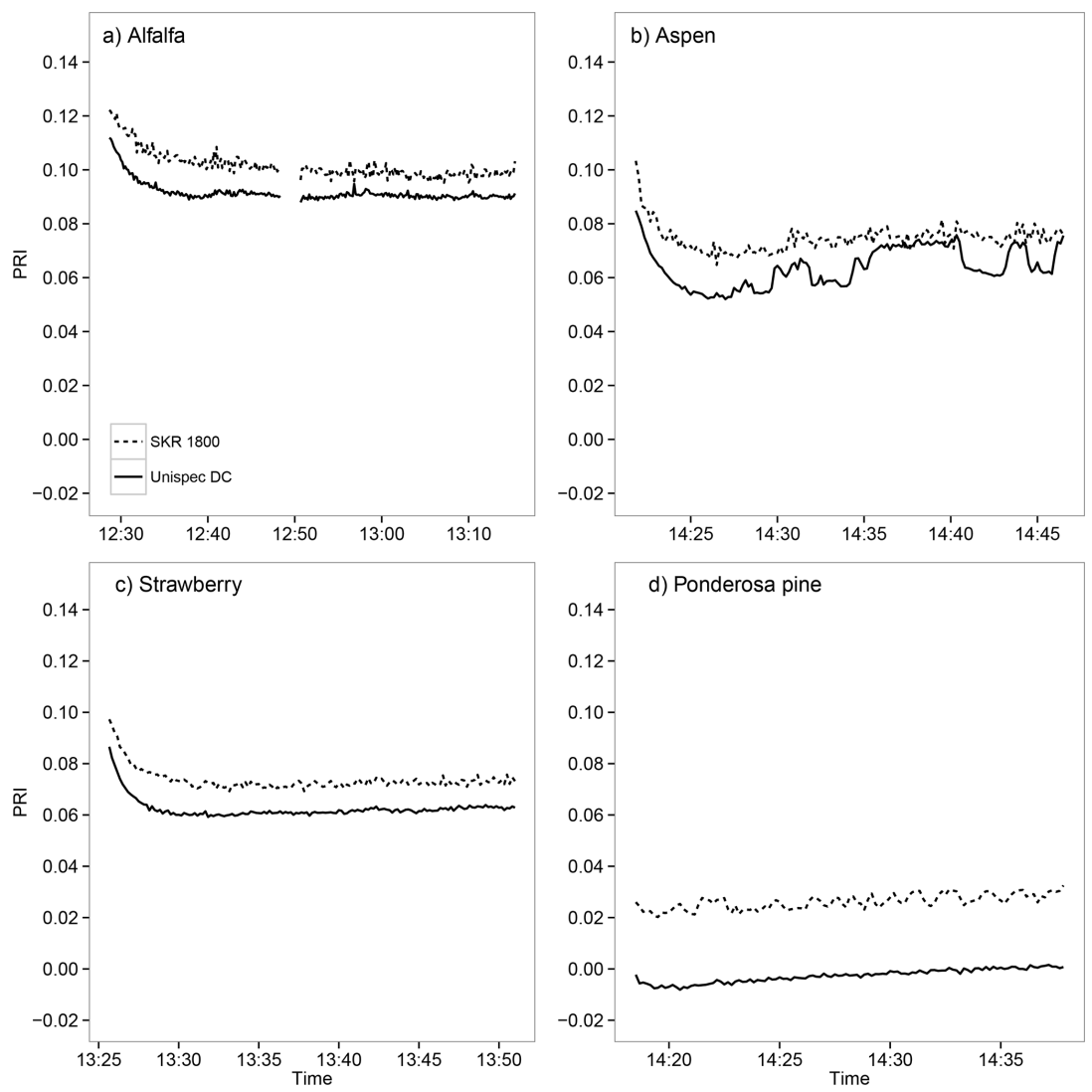

Figure 5. Photochemical reflectance index (PRI) response to a dark-to-light transition for (a) alfalfa (Medicago sativa), (b) aspen (Populus tremuloides), (c) strawberry (Fragaria $\times$ ananassa), and (d) ponderosa pine (Pinus ponderosa), as recorded by a UniSpec DC instrument and the SKR 1800 sensor pair. Data shown are those that have been corrected to normalize the SRF differences between instruments.

differences were magnified when illumination conditions became more erratic during the late afternoon.

\subsubsection{Tracking physiological change}

Figure 9 illustrates the diurnal PRI and EPS patterns of individual needle leaves sampled from each of the four corners of the pine canopy. Temporal changes were most pronounced in leaves located in the southern corners of the sampling plot. Over the course of the experiment these leaves were exposed to higher light levels for a longer duration and showed a clear decrease in both PRI and EPS as illumination increased during the early to mid-afternoon, before gradually increasing towards the early evening. A similar decrease in the PRI during the early to mid-afternoon was observed at the canopyscale by the SKR 1800 sensors, although a less prominent pattern was observed by the UniSpec instrument (Fig. 9).

The PRI was significantly correlated with EPS both at the leaf and at the canopy level (Fig. 10). The strongest correlations were observed at the canopy-scale when PRI was measured with the UniSpec instrument $\left(r^{2}=0.76\right)$, and weakest when using the SKR 1800 sensors $\left(r^{2}=0.46\right)$. Differences in instrument SRFs did not influence the strength of the correlations between EPS and the UniSpec canopy PRI, and UniSpec leaf PRI (after SRF corrections were applied, $r^{2}=0.77, p<0.001$ and $r^{2}=0.56, p<0.01$, respectively (data not shown)).

We calculated the NDVI from the UniSpec canopy data to explore whether the PRI was influenced by diurnal changes in plant canopy architecture. The results showed that there was no correlation between NDVI and EPS $\left(r^{2}=0.007\right.$; data not shown), indicating that the diurnal variation observed in the canopy PRI was not simply a consequence of changing canopy architecture but instead reflected actual changes in the xanthophyll cycle related to altered photosynthetic activity.

\section{Discussion}

Our results suggest that under environmental conditions (e.g. temperature and relative humidity) similar to those observed in the current study, both the UniSpec and SKR 1800 instruments are able to track changes in the PRI signal in response to short-term (or facultative) plant responses to changing illumination conditions. Differences between the 

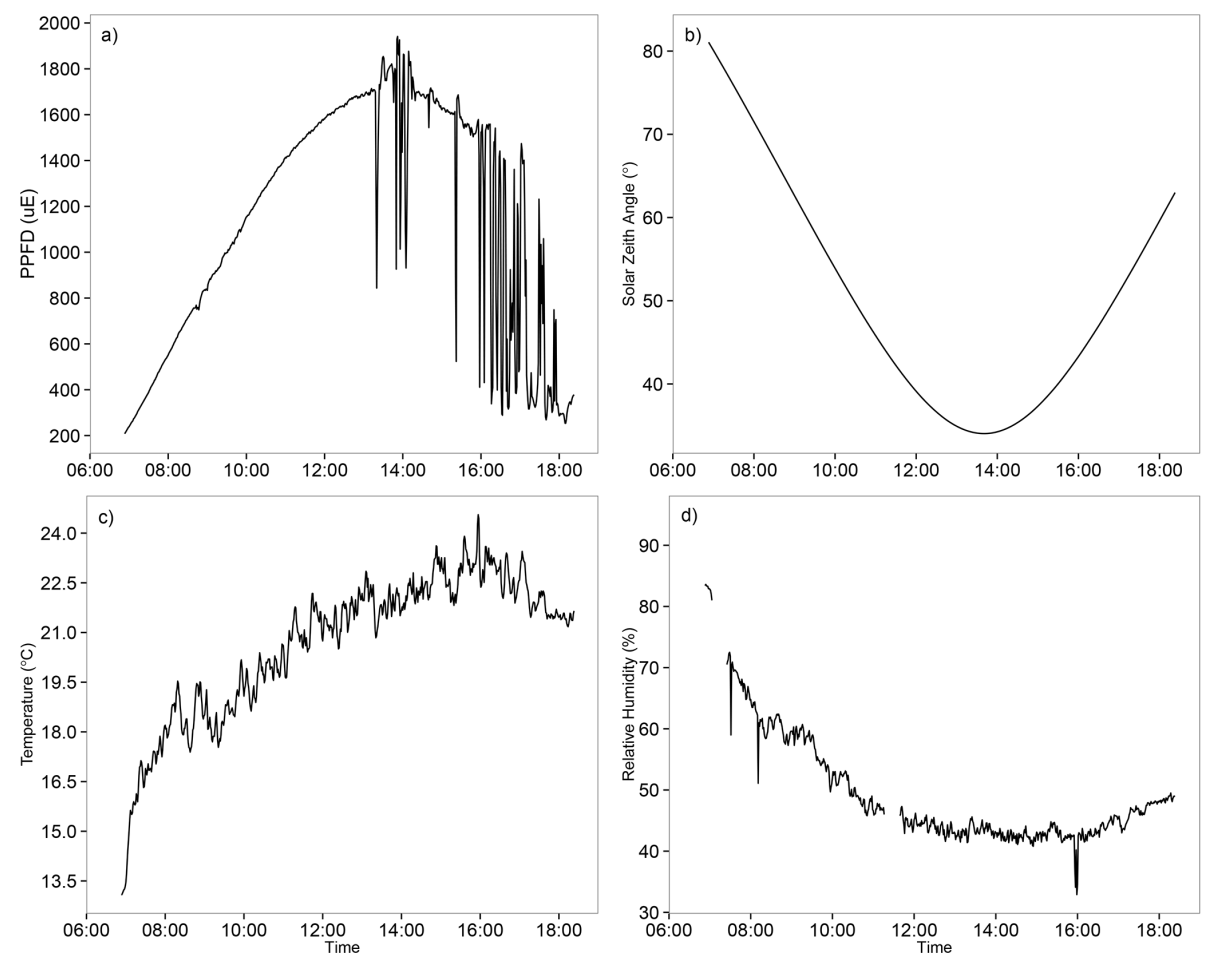

Figure 6. (a) Photosynthetic photon flux density (PPFD), (b) solar zenith angle (SZA), (c) temperature and (d) relative humidity as a function of time of day (July 25, 2013).

values of the PRI obtained from each instrument were significant, but generally consistent across a range of species and canopy architectures. Although the centre wavelengths of each of the SKR 1800 channels were located very close to the standard $531 \mathrm{~nm}$ and $570 \mathrm{~nm}$ wavelengths commonly used to calculate the PRI, the SRFs of the two instruments were different (Fig. 1). For the SKR 1800 sensor pair, these differences resulted in a higher HCRF at $531 \mathrm{~nm}$, a region where changing absorption takes place due to the activity of xanthophyll pigments, than at the reference wavelength of $570 \mathrm{~nm}$; this is opposite to that observed by the UniSpec instruments. Simulating the SKR 1800 measurements from the UniSpec via convolution resulted in PRI values from both instruments that were more similar, although statistically significant differences remained. Differences in the SRFs between instruments are common and not confined to the two instruments used in this study. Castro-Esau et al. (2006) compared a range of spectral indices obtained from multiple industry-standard spectrometers and also found values of the PRI to be particularly sensitive to instrument configuration. One possible reason for the remaining differences in PRI values post convolution in the current study may be that the corresponding spectral channels on the upward and downward facing SKR 1800 sensors are not identical, i.e. their SRFs differ (Fig. 1). This was not accounted for in the spectral convolution, which only used the SRFs generated for the downward facing sensor. Even though great care was taken to match the ground resolution element observed by each instrument, small differences in the area of the canopy that was observed may also remain.

Diurnal patterns of PRI, showing a decline in PRI towards midday and a recovery during late afternoon, were similar to those reported by other studies (e.g. Gamon et al., 1992; Filella et al., 1996). Anomalously high canopy PRI values were noted in the early morning when SZAs exceeded $\sim 60^{\circ}$, although the reasons for such values are likely to be instrumental and a combination of a low signal-to-noise ratio under low light conditions and the departure of the white reference panel and SKR 1800 cosine diffuser from true cosine behaviour at high SZAs (e.g. Duggin, 1980). Consequently the collection of data when the SZA is high or illumination conditions are highly variable is not recommended.

The physiological PRI responses reported here from the dark-to-light transition experiments are similar to those of others (Gamon et al., 1990, 1992; Gamon and Berry, 2012; Hmimina et al., 2014). All species showed a decline in the PRI as plants were exposed to rapid increases in illumination, suggesting changes in the epoxidation state of the xanthophyll cycle in response to increased sun exposure (Demmig-Adams, 1990). The very low dynamic range of the PRI observed for the ponderosa pine canopy (Fig. 5d) was most likely a consequence of the saplings becoming excessively hot under the black cloth prior to the 


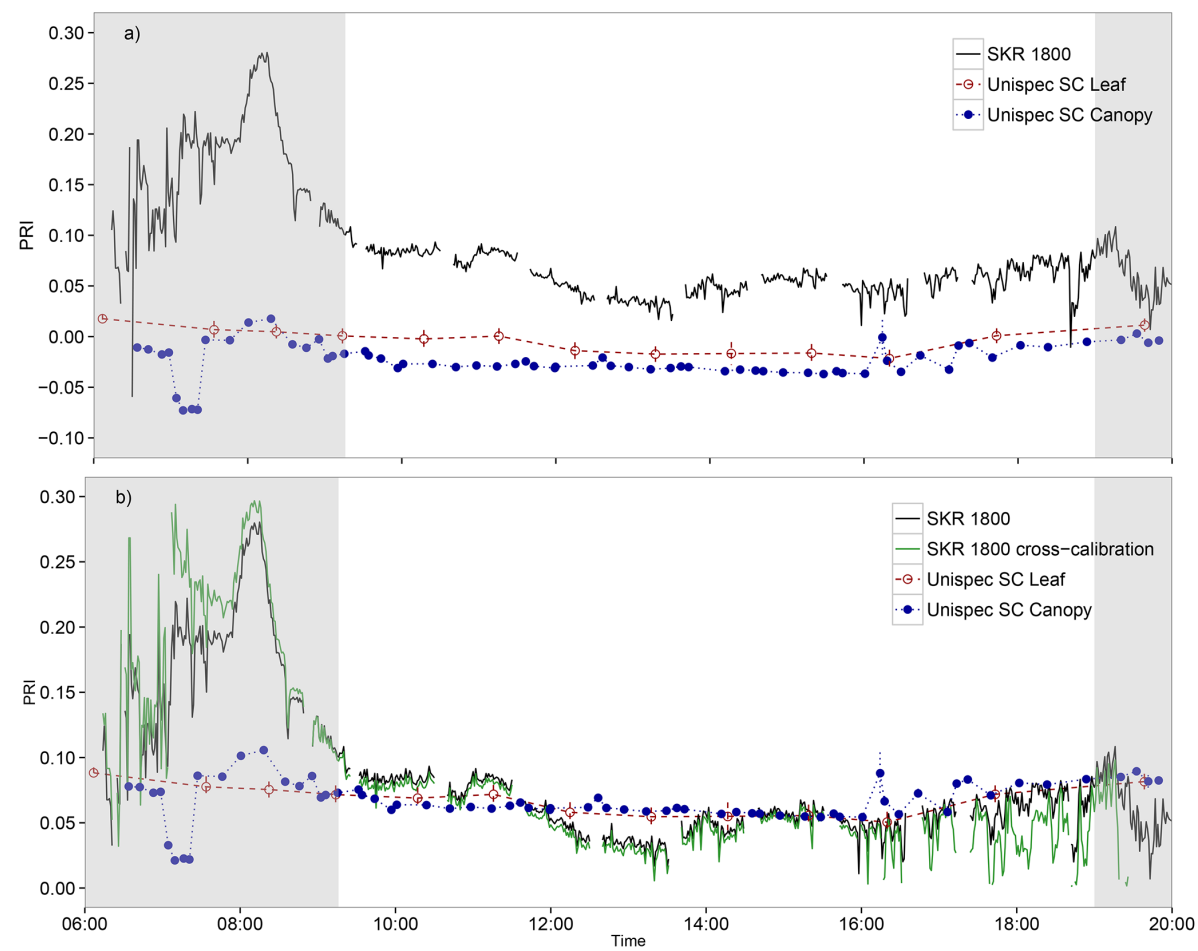

Figure 7. Lodgepole pine (Pinus contorta) canopy and leaf photochemical reflectance index (PRI) as a function of time of day. Mean values for each sampling period are shown for both UniSpec instruments and the error bars represent \pm 1 standard error (SE). Panel (a) shows the original data values and the shaded areas indicate times of day where the solar zenith angle (SZA) exceeds $60^{\circ}$. Panel (b) shows data that have been corrected to normalize the SRF differences between instruments and the shaded areas indicate times of day beyond those used for generating the SKR 1800 cross-calibration functions using white panels.

experimentalmeasurements, which lead to the visible death of many top canopy leaves by the end of the experiment.

After normalization for different instrument SRFs, instrument differences between PRI values were similar for all canopies, apart from the ponderosa pine where the PRI measured by the SKR 1800 sensors was often double that recorded by the UniSpec (Fig. 4). Due to the death of many of the top canopy leaves during the canopy shading, the PRI remained extremely low throughout the experiment (Fig. 5d) and thus the large between-instrument differences in index values may be a consequence of a low signal-to-noise ratio for the SKR 1800 sensors under conditions where the reflectance signal is weak.

Even though the PRI is often used as an indicator of photosynthetic efficiency in many remote sensing studies, few studies actually relate the index to the changes in the xanthophyll pigment pool, which it aims to detect (e.g. Gamon et al., 1990, 1992, 2001; Filella et al., 1996; Gamon and Berry, 2012). Significant correlations were observed between diurnal changes in EPS and PRI at both the canopy level and leaf level (Fig. 10), and indicate leaf responses are also detectable on a canopy scale with both instruments. These results are similar to previous diurnal studies by Gamon et al. (1992) and Filella et al. (1996).
The strength of the relationship between PRI and EPS measured at the leaf level was weaker than that measured at the canopy scale using a similar UniSpec instrument. Diurnal PRI patterns at the leaf level were largely dominated by leaves sampled from plants facing south, but also included measurements from leaves exposed to lower levels of illumination where diurnal changes in EPS and PRI were minimal (Fig. 9). Consequently relationships between leaflevel PRI and EPS were stronger for south facing leaves $\left(r^{2}=0.73, p<0.05\right.$ and $r^{2}=0.43, p<0.05$; for the southwest and southeast facing leaves respectively) than those facing north $\left(r^{2}=0.07, p=0.5\right.$ and $r^{2}=0.12, p=0.4$; for the northwest and northeast facing leaves respectively). Both temporal patterns were incorporated into the mean values of EPS and PRI, which introduced scatter into the leaf-level EPS-PRI regression and thus weakened the overall relationship (Fig. 10). Differences in the linear regression coefficients of the EPS-PRI relationship for the leaf and canopy, when using similar UniSpec instruments, were also apparent. Such differences may have resulted from the use of two different UniSpec instruments, which were not cross-calibrated, but may also be a consequence of comparing leaf-level measurements made under controlled illumination conditions with those obtained from an entire canopy 


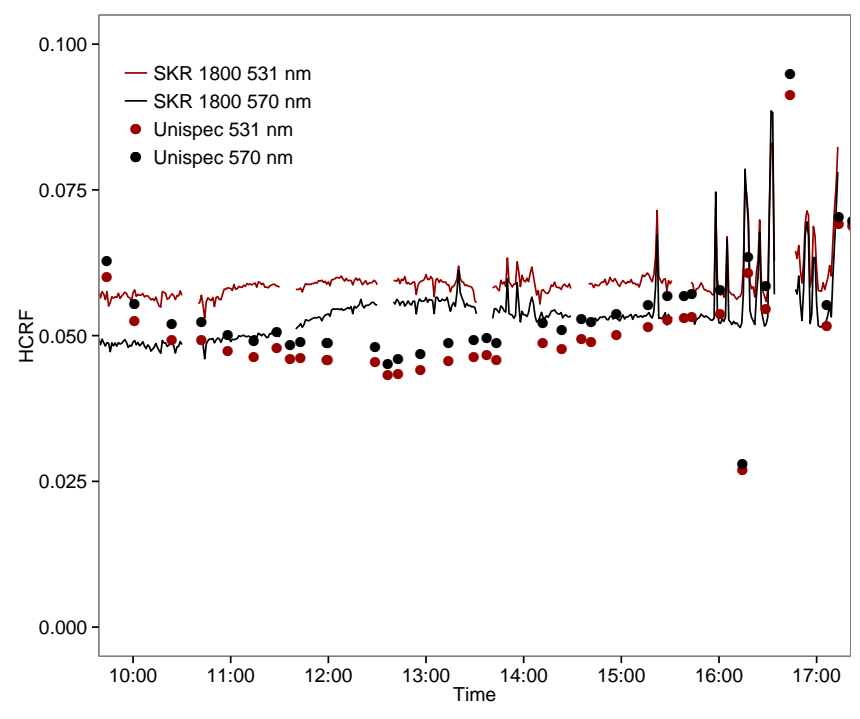

Figure 8. Hemispherical-conical reflectance factors (HCRFs) at 531 and $570 \mathrm{~nm}$ obtained by a UniSpec and SKR 1800 sensor pair, as a function of time of day. Data were collected over a lodgepole pine (Pinus contorta) canopy and corrected to reflectance using cross-calibration functions determined from white panel measurements. Only data that were collected within the time frame of white panel measurements are shown. Data shown have not been normalized to correct for the SRF differences between instruments.

under natural sunlight. Similar offsets in PRI values between leaf levels and canopy levels have been reported previously (e.g. Gamon and Qiu, 1999).

Canopy PRI obtained by both the SKR 1800 and UniSpec instruments predominantly reflected changes in the sunexposed canopy. However, the SKR 1800 sensors recorded a prominent decrease in the PRI during the early afternoon (Fig. 7). This pattern was also reflected in some of the more southerly facing leaf-level measurements and coincided with increased variability in the measures of the EPS. Consequently the observed between-sensor differences are likely due to each sensor having a slightly different FOV. The complexity of the conifer canopy is such that even relatively small differences in the FOV between instruments may result in each instrument measuring parts of the canopy that may have been exposed to different levels of illumination (i.e. levels of sun and shade; Gamon and Bond, 2013).

Although differences in the spectral configuration of the two instruments resulted in significantly different PRI values, the strength of the EPS-PRI relationship for the UniSpec instruments prior to and after applying the SRF corrections, was not significantly different. Early work on the initial formulation of the PRI (e.g. Gamon et al., 1992) showed that there may not be a single optimum reference wavelength for the PRI equation. In these early studies, using a Spectron instrument (FWHM $\sim 10 \mathrm{~nm}$ ), Gamon et al. (1992) showed that significant correlations between EPS and PRI could be obtained using a reference wavelength within the $\sim 550$ to $\sim 570 \mathrm{~nm}$ range. Consequently, whilst the SRF centred at $\sim 570 \mathrm{~nm}$ differed between the SKR 1800 and UniSpec instruments, resulting in differences in the wavelengths and relative contribution of light to the $570 \mathrm{~nm}$ radiance measurements, the light contributing to the reference wavelength for each instrument was within the optimum range reported by Gamon et al. (1992). However, even when the SKR 1800 sensors were simulated by the UniSpec canopy instrument, the diurnal pattern did not match that of the actual SKR 1800 sensors and the EPS-PRI relationship was consistently stronger than the relationship observed between EPS and the SKR 1800-measured PRI suggesting that instrument differences other than the spectral response (e.g. signal-to-noise ratio, FOV, the use of a cosine diffuser compared to a white reference panel, the quality of the optics) may also have contributed to the observed divergence in diurnal PRI values between instruments. Further inter-comparison studies, which utilize more uniform vegetation canopies (e.g. Anderson et al., 2013) would help clarify the exact reasons for these observed sensor differences.

\section{Concluding remarks}

Near-surface optical sampling can be used to complement existing vegetation and micrometeorological measurements to enable assessment of biogeochemical processes over a range of spatial scales. Sensors that are capable of measuring reflectance across narrow spectral bands are of particular interest for monitoring changes in plant physiological processes (e.g. the photochemical reflectance index: PRI) linked to carbon exchange and photosynthetic downregulation via xanthophyll cycle pigments. The cost of unattended optical instruments is now such that these instruments are increasingly being deployed for long term monitoring. However, a full characterization of these sensors is necessary if the data are to be compared across geographical locations, over time and between instruments. Specifically, it is critical that the SKR 1800 sensors used have matching wavelengths and the same spectral response. Ideally, this could be confirmed by the manufacturer or by independent laboratory tests. If independent automated spectrometers were also on site, then it would be possible to simulate the SKR 1800 response to understand the sources of any differences that might occur. All sensors deployed should be mounted at similar distances from the canopy and at similar angles. They should be checked and cleaned annually and, according to the manufacturer's recommendations, returned for laboratory calibration every two years. Additional corrections, for dark-current drift and temperature drift in response to large variations in temperature, may also be required (Eklundh et al., 2011). Regular cross-calibration could be used to assess and possibly correct for such instrument drift.

In this paper, we compared the physical capabilities of two brands of field-portable narrowband instruments commonly 

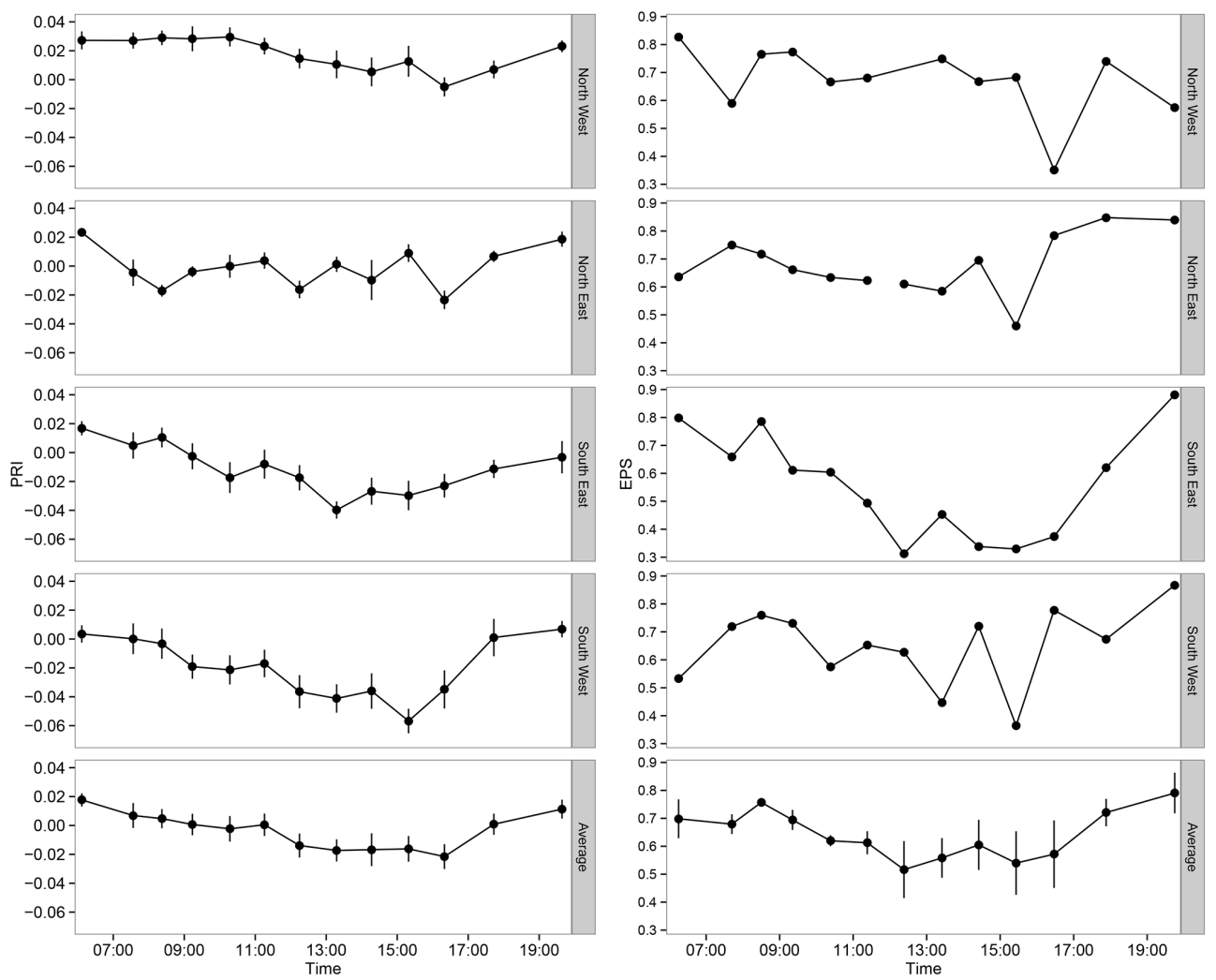

Figure 9. Diurnal course of lodgepole pine (Pinus contorta) leaf-level photochemical reflectance index (PRI) and the epoxidation state of the xanthophyll cycle components (EPS). PRI values for each of the four directions are means of 10 sampled spectra. Error bars represent \pm 1 standard error of mean.

used to measure PRI, namely the UniSpec spectroradiometer (PP Systems, USA) and SKR 1800 (Skye Instruments, UK). The shade-removal experiments revealed that both instruments were able to track rapid apparent changes in the epoxidation state of xanthophyll cycle pigments, although the dynamic range of the PRI was lower for the SKR 1800 sensors, suggesting a lower sensitivity to changes in xanthophyll cycle pigments related to photosynthetic activity. The PRI values measured from each instrument were subject to a systematic difference (bias), the magnitude of which appeared to be generally consistent across the range of species studied and could primarily be explained by differences in the spectral configuration of each instrument.

Despite the recent proliferation in the use of SKR 1800 unattended PRI sensors, to the best of our knowledge there are no published data reporting relationships between the PRI measurements obtained from this instrument and actual changes in xanthophyll pigments. In this study, the diurnal course of the PRI obtained from both the UniSpec and SKR 1800 instruments compared well with leaf-level HCRF measurements and physical measures of the EPS. However, both instruments were susceptible to the well-documented issues associated with the collection of spectral data at high solar zenith angles $\left(>60^{\circ}\right)$ and under fluctuating illumination con- ditions independent of whether the mode of operation was dual or single channel (SKR 1800 and UniSpec SC, respectively). The findings suggest that the SKR 1800 sensors can be used for tracking short-term facultative changes in plant photosynthetic activity, although the apparent lower sensitivity of the instrument to changes in EPS weakens the relationship in comparison to the more expensive instruments.

The collective results clearly indicate the importance of characterizing the physical capabilities of sensors before field deployment. The spectral configuration of the SKR 1800 sensor pair is often dependent on the customer's preferred bandwidth (e.g. 5 or $10 \mathrm{~nm}$ ) and the manufacturer's selection of filters, such that different SKR 1800 sensor pairs may also give PRI values that are not directly comparable. Consequently the physiological interpretation of the PRI values should be undertaken with care, particularly when data from different instruments or sites are being compared.

Data collected at high solar zenith angles are unlikely to be related to physiological changes in the vegetation canopy and the sensitive nature of the PRI signal is such that values obtained under varying illumination conditions could also be subject to large errors. These errors can be eliminated or reduced at the leaf level by using active methods (e.g. using the artificial light source provided with a leaf clip), and 


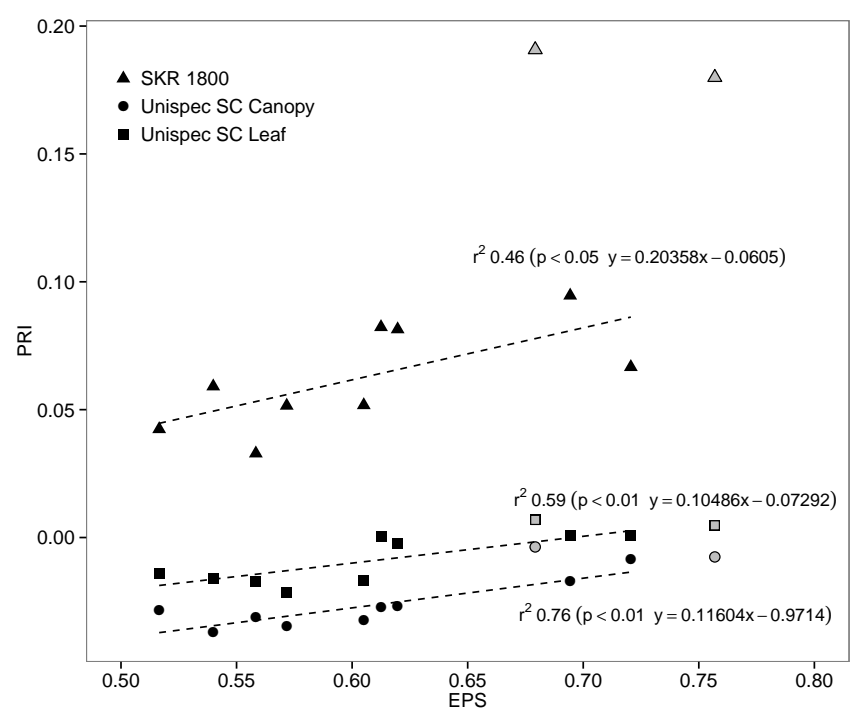

Figure 10. The photochemical reflectance index (PRI) as a function of the epoxidation state of the xanthophyll cycle components (EPS) for a lodgepole pine (Pinus contorta) canopy and individual leaves as measured by several different instruments. EPS and UniSpec SC leaf values are the means of the sampled plot corners ( $n=4$ and $n=40$; respectively), UniSpec SC canopy values are the mean of the PRI measurements collected coincident to the leaflevel measurements $(n=3$; collected over $<60$ s) and SKR 1800 values are single values corresponding to the same time period. Symbols shaded in grey represent measurements collected at a time when the solar zenith angle was $>60^{\circ}$ and have been excluded from the regressions, for both canopy and leaf-level measurements. Data shown have not been normalized to correct for the SRF differences between instruments.

additionalefforts to develop active PRI measurements, such as the use of green lasers centred at $532 \mathrm{~nm}$, might help reduce these illumination errors at the canopy scale (e.g. Magney et al., 2014).

Although the strength of the relationship between the SKR 1800 PRI and the epoxidation state of the xanthophyll cycle (EPS) was weaker than those obtained from more expensive instruments, at seasonal timescales variations in PRI may be larger than diurnal changes (e.g. Sims et al., 2006) and thus more easily detected by the SKR 1800 . At these longer timescales, the PRI has been shown to be an indicator of constitutive pool size changes in pigment content as opposed to rapid xanthophyll cycle pigment activity (Stylinski et al., 2002; Garrity et al., 2011; Porcar-Castell et al., 2013; Wong and Gamon, 2014) and thus data from these sensors could help to elucidate how plants respond to changing environmental and physiological conditions across multiple temporal scales, and aid in the development of improved PRI-based photosynthesis models. However, further work is required regarding the temperature dependency and long-term stability of such sensors, especially if data are to be compared across seasons.
In conclusion, the SKR 1800 sensors were able to track changes in the PRI in a consistent manner across a range of plant canopies and, if combined with contextual information such as the expected range in PRI values for healthy/stressed canopies, PRI data from these sensors could be used to effectively monitor dynamic changes in vegetation physiology.

Acknowledgements. The work was partially supported by a EUROSPEC - Cost Action ES0903 Short Term Scientific Mission grant (awarded to A. Harris). Additional support was provided by an NSERC Discovery Grant, an iCORE/AITF award and a CFI grant (awarded to J.A. Gamon). Olga Kovalchuk (University of Alberta, Canada) and Enrica Nestola (Institute of AgroEnvironmental $\&$ Forest Biology, National Research Council, Porano, Italy) are also thanked for their help during the fieldwork.

Edited by: G. Wohlfahrt

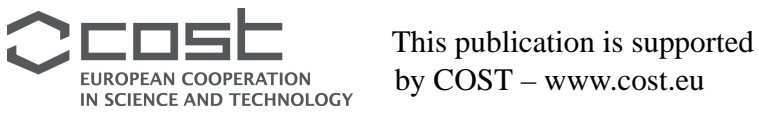

\section{References}

Anderson, K., Rossini, M., Pacheco-Labrador, J., Balzarolo, M., Mac Arthur, A., Fava, F., Julitta, T., and Vescovo, L.: Intercomparison of hemispherical conical reflectance factors (HCRF) measured with four fibre-based spectrometers, Optics Express, 21, 605-617, 2013.

Baldocchi, D., Falge, E., Gu, L. H., Olson, R., Hollinger, D., Running, S., Anthoni, P., Bernhofer, C., Davis, K., Evans, R., Fuentes, J., Goldstein, A., Katul, G., Law, B., Lee, X. H., Malhi, Y., Meyers, T., Munger, W., Oechel, W., U, K. T. P., Pilegaard, K., Schmid, H. P., Valentini, R., Verma, S., Vesala, T., Wilson, K., and Wofsy, S.: FLUXNET: A new tool to study the temporal and spatial variability of ecosystem-scale carbon dioxide, water vapor, and energy flux densities, Bull. Am. Meteorol. Soc., 82, 2415-2434, 2001.

Castro-Esau, K. L., Sanchez-Azofeifa, G. A., and Rivard, B.: Comparison of spectral indices obtained using multiple spectroradiometers, Remote Sens. Environ., 103, 276-288, 2006.

Cheng, Y. B., Middleton, E. M., Huemmrich, K. F., Zhang, Q. Y., Campbell, P. K. E., Corp, L. A., Russ, A. L., and Kustas, W. P.: Utilizing in situ directional hyperspectral measurements to validate bio-indicator simulations for a corn crop canopy, Ecol. Inform., 5, 330-338, 2010.

Duggin, M. J.: The field measurement of reflectance factors, Photogramm. Eng. Rem. Sens., 46, 643-647, 1980.

Demmig-Adams, B.: Carotenoids and photoprotection in plants A role for the xanthophyll zeaxanthin, Biochim. Biophys. Acta, 1020, 1-24, 1990.

Eklundh, L., Jin, H., Schubert, P., Guzinski, R., and Heliasz, M.: An optical sensor network for vegetation phenology monitoring and satellite data calibration, Sensors, 11, 7678-7709, 2011.

Erdle, K., Mistele, B., and Schmidhalter, U.: Comparison of active and passive spectral sensors in discriminating biomass parameters and nitrogen status in wheat cultivars, Field Crops Res., 124, 74-84, 2011. 
Filella, I., Amaro, T., Araus, J. L., and Peñuelas, J.: Relationship between photosynthetic radiation-use efficiency of Barley canopies and the photochemical reflectance index (PRI), Physiol. Plant., 96, 211-216, 1996.

Fitzgerald, G. J.: Characterizing vegetation indices derived from active and passive sensors, Int. J. Remote Sens., 4335-4348, 2010.

Gamon, J. A. and Berry, J. A.: Facultative and constitutive pigment effects on the Photochemical Reflectance Index (PRI) in sun and shade conifer needles, Isrl. J. Plant Sci., 60, 85-95, 2012.

Gamon, J. A. and Bond, B.: Effects of irradiance and photosynthetic downregulation on the photochemical reflectance index in Douglas-fir and ponderosa pine, Remote Sens. Environ., 135, 141-149, 2013.

Gamon, J. A. and Qiu, H. L.: Ecological applications of remote sensing at multiple scales, Handbook of Functional Plant Ecology, 805-846, 1999.

Gamon, J. A., Field, C. B., Bilger, W., Bjorkman, O., Fredeen, A. L., and Peñuelas, J.: Remote sensing of xanthophyll cycle and chlorophyll fluorescence in sunflower leaves and canopies, Oecologia, 85, 1-7, 1990.

Gamon, J. A., Peñuelas, J., and Field, C. B.: A narrow-waveband spectral index that tracks diurnal changes in photosynthetic efficiency, Remote Sens. Environ., 41, 35-44, 1992.

Gamon, J. A., Filella, I., and Peñuelas, J.: The dynamic $531 \mathrm{~nm} \Delta$ reflectance signal: A survey of twenty angiosperm species, Curr. Top. Plant Physiol., 8, 172-177, 1993.

Gamon, J. A. and Surfus, J. S.: Assessing leaf pigment content and activity with a reflectometer, New Phytol., 143, 105-117, 1999.

Gamon, J. A., Field, C. B., Fredeen, A. L., and Thayer, S.: Assessing photosynthetic downregulation in sunflower stands with an optically-based model, Photosynth. Res., 67, 113-115, 2001.

Gamon, J. A., Cheng, Y., Claudio, H., MacKinney, L., and Sims, D. A.: A mobile tram system for systematic sampling of ecosystem optical properties, Remote Sens. Environ., 103, 246-254, 2006a.

Gamon, J. A., Rahman, A. F., Dungan, J. L., Schildhauer, M., and Huemmrich, K. F.: Spectral Network (SpecNet) - What is it and why do we need it?, Remote Sens. Environ., 103, 227-235, $2006 b$.

Garbulsky, M. F., Peñuelas, J., Gamon, J., Inoue, Y., and Filella, I.: The photochemical reflectance index (PRI) and the remote sensing of leaf, canopy and ecosystem radiation use efficiencies: A review and meta-analysis, Remote Sens. Environ., 115, 281-297, 2011

Garrity, S. R., Eitel, J. U. H., and Vierling, L. A.: Disentangling the relationships between plant pigments and the photochemical reflectance index reveals a new approach for remote estimation of carotenoid content, Remote Sens. Environ., 115, 628-635, 2011.

Gitelson, A. A., Vina, A., Ciganda, V., Rundquist, D. C., and Arkebauer, T. J.: Remote estimation of canopy chlorophyll content in crops, Geophys. Res. Lett., 32, L08403, doi:10.1029/2005GL022688, 2005.

Harris, A. and Dash, J.: The potential of the MERIS Terrestrial Chlorophyll Index for carbon flux estimation, Remote Sens. Environ., 114, 1856-1862, 2010.

Hilker, T., Gitelson, A., Coops, N., Hall, F., and Black, T.: Tracking plant physiological properties from multi-angular tower-based remote sensing, Oecologia, 165, 865-876, 2011.

Hill, M. J., Held, A. A., Leuning, R., Coops, N. C., Hughes, D., and Cleugh, H. A.: MODIS spectral signals at a flux tower site: Re- lationships with high-resolution data, and $\mathrm{CO}_{2}$ flux and light use efficiency measurements, Remote Sens. Environ., 103, 351-368, 2006.

Hmimina, G., Dufrene, E., Pontailler, J. Y., Delpierre, N., Aubinet, M., Caquet, B., de Grandcourt, A., Burban, B., Flechard, C., Granier, A., Gross, P., Heinesch, B., Longdoz, B., Moureaux, C., Ourcival, J. M., Rambal, S., Saint Andre, L., and Soudani, K.: Evaluation of the potential of MODIS satellite data to predict vegetation phenology in different biomes: An investigation using ground-based NDVI measurements, Remote Sens. Environ., 132, 145-158, 2013.

Hmimina, G., Dufrene, E., and Soudani, K.: Relationship between photochemical reflectance index and leaf ecophysiological and biochemical parameters under two different water statuses: towards a rapid and efficient correction method using real-time measurements, Plant Cell Environ., 37, 473-487, 2014.

Huemmrich, K. F., Gamon, J. A., Tweedie, C. E., Oberbauer, S. F., Kinoshita, G., Houston, S., Kuchy, A., Hollister, R. D., Kwon, H., Mano, M., Harazono, Y., Webber, P. J., and Oechel, W. C.: Remote sensing of tundra gross ecosystem productivity and light use efficiency under varying temperature and moisture conditions, Remote Sens. Environ., 114, 481-489, 2010.

Jin, H. and Eklundh, L.: Guidelines for multispectral measurement of vegetation, ver 1.0, Lund University, 2013.

Jung, M., Reichstein, M., Margolis, H. A., Cescatti, A., Richardson, A. D., Arain, M. A., Arneth, A., Bernhofer, C., Bonal, D., Chen, J., Gianelle, D., Gobron, N., Kiely, G., Kutsch, W., Lasslop, G., Law, B. E., Lindroth, A., Merbold, L., Montagnani, L., Moors, E. J., Papale, D., Sottocornola, M., Vaccari, F., and Williams, C.: Global patterns of land-atmosphere fluxes of carbon dioxide, latent heat, and sensible heat derived from eddy covariance, satellite, and meteorological observations, J. Geophys. Res. 116, G00J07, doi:10.1029/2010JG001566, 2011.

Liu, J., Chen, J. M., Cihlar, J., and Chen, W.: Net primary productivity distribution in the BOREAS region from a process model using satellite and surface data, J. Geophys. Res., 104, 27735-27754, 1999.

Magney, T. S., Eusden, S. A., Eitel, J. U. H., Logan, B. A., Jiang, J., and Vierling, L. A.: Assessing leaf photoprotective mechanisms using terrestrial LiDAR: towards mapping canopy photosynthetic performance in three dimensions, New Phytol., 201, 344-356, 2014.

Milton, E. J., Schaepman, M. E., Anderson, K., Kneubühler, M., and Fox, N.: Progress in field spectroscopy, Remote Sens. Environ., 113, Supplement 1, S92-S109, 2009.

Monteith, J. L. and Moss, C. J.: Climate and efficiency of crop production in Britain, Philosoph. Transact. Roy. Soc. London Ser.B, 281, 277-294, 1977.

Myneni, R. B., Nemani, R. R., and Running, S. W.: Estimation of global leaf area index and absorbed par using radiative transfer models, IEEE Trans. Geosci. Remote Sens., 35, 1380-1393, 1997.

Pacheco-Labrador, J. and Martin, M.P.: Nonlinear response in a field portable spectroradiometer: Characterization and effects on output reflectance, IEEE Trans. Geosci. Remote Sensing, 52, 920-928, 2014.

Peñuelas J., Filella I., and Gamon J. A.: Assessment of photosynthetic radiation-use efficiency with spectral reflectance, New Phytol., 131, 291-296, 1995. 
Porcar-Castell, A., Garcia-Plazaola, J., Nichol, C., Kolari, P., Olascoaga, B., Kuusinen, N., Fernández-Marín, B., Pulkkinen, M., Juurola, E., and Nikinmaa, E.: Physiology of the seasonal relationship between the photochemical reflectance index and photosynthetic light use efficiency, Oecologia, 170, 313-323, 2012.

$\mathrm{R}$ Development Core Team: R: A language and environment for statistical computing, R Foundation for Statistical Computing,Vienna, Austria, ISBN 3-900051-07-0, http://www. R-project.org/, 2012.

Reichstein, M., Ciais, P., Papale, D., Valentini, R., Running, S., Viovy, N., Cramer, W., Granier, A., Ogee, J., Allard, V., Aubinet, M., Bernhofer, C., Buchmann, N., Carrara, A., Grunwald, T., Heimann, M., Heinesch, B., Knohl, A., Kutsch, W., Loustau, D., Manca, G., Matteucci, G., Miglietta, F., Ourcival, J. M., Pilegaard, K., Pumpanen, J., Rambal, S., Schaphoff, S., Seufert, G., Soussana, J. F., Sanz, M. J., Vesala, T., and Zhao, M.: Reduction of ecosystem productivity and respiration during the European summer 2003 climate anomaly: a joint flux tower, remote sensing and modelling analysis, Glob. Change Biol., 13, 634-651, 2007.

Robinson, I. and MacArthur, A. The Field Spectroscopy Facility Post Processing Toolbox User Guide: Post processing spectral data in MATLAB, 1-26, 2011.

Roden, J. and Pearcy, R. W.: Effect of leaf flutter on the light environment of poplars, Oecologia, 93, 201-207, 1992.

Rollin, E. M., Emmery, D. R., Kerr, C. D., and Milton, E. J.: Dualbeam reflectance measurements and the need for a field intercalibration procedure, Proceedings of RSS'98: Developing International Connections, Nottingham, UK, 552-558, 1998.

Rossini, M., Cogliati, S., Meroni, M., Migliavacca, M., Galvagno, M., Busetto, L., Cremonese, E., Julitta, T., Siniscalco, C., di Cella, U. M., and Colombo, R.: Remote sensing-based estimation of gross primary production in a subalpine grassland, Biogeosciences, 9, 2565-2584, doi:10.5194/bg-9-2565-2012, 2012.

Running, S. W., Nemani, R. R., Heinsch, F. A., Zhao, M. S., Reeves, M., and Hashimoto, H.: A continuous satellite-derived measure of global terrestrial primary production, Bioscience, 54, 547-560, 2004.

Sims, D. A., Luo, H. Y., Hastings, S., Oechel, W. C., Rahman, A. F., and Gamon, J. A.: Parallel adjustments in vegetation greenness and ecosystem $\mathrm{CO}_{2}$ exchange in response to drought in a Southern California chaparral ecosystem, Remote Sens. Environ., 103, 289-303, 2006.
Smith, G. M. and Milton, E. J.: The use of the empirical line method to calibrate remotely sensed data to reflectance, Int. J. Remote Sens., 20, 2653-2662, 1999.

Soudani, K., Hmimina, G., Delpierre, N., Pontailler, J. Y., Aubinet, M., Bonal, D., Caquet, B., de Grandcourt, A., Burban, B., Flechard, C., Guyon, D., Granier, A., Gross, P., Heinesh, B., Longdoz, B., Loustau, D., Moureaux, C., Ourcival, J. M., Rambal, S., Saint Andre, L., and Dufrene, E.: Ground-based network of NDVI measurements for tracking temporal dynamics of canopy structure and vegetation phenology in different biomes, Remote Sens. Environ., 123, 234-245, 2012.

Stoy, P. C., Williams, M., Evans, J. G., Prieto-Blanco, A., Disney, M., Hill, T. C., Ward, H. C., Wade, T. J., and Street, L. E.: Upscaling tundra $\mathrm{CO}_{2}$ exchange from chamber to eddy covariance tower, Arct. Antarct. Alp. Res., 45, 275-284, 2013.

Stylinski, C., Gamon, J., and Oechel, W.: Seasonal patterns of reflectance indices, carotenoid pigments and photosynthesis of evergreen chaparral species, Oecologia, 131, 366 pp., 2002.

Thayer, S. S. and Bjorkman, O.: Leaf xanthophyll content and composition in sun and shade determined by HPLC Photosynth. Res. 23, 331-343, 1990.

Turner, D., Urbanski, S., Bremwe, D., Wofsy, S. C., Meyers, T., Gower, S. T., and Gregory, M.: A cross-biome comparison of daily light use efficiency for gross primary production, Glob. Change Biol., 9, 383-395, 2003.

Venables, W. N. and Ripley, B. D.: Modern Applied Statistics with S. Fourth Edition. Springer, New York, ISBN 0-387-95457-0, 2002.

Williams, M., Bell, R., Spadavecchia, L., Street, L. E., and Van Wijk, M. T.: Upscaling leaf area index in an Arctic landscape through multiscale observations, Glob. Change Biol., 14, 1517-1530, 2008.

Wong, C. and Gamon, J.: Three sources of variation in the Photochemical Reflectance Index (PRI) in evergreen conifers, New Phytol., doi:10.1111/nph.13159, 2014.

Wright, P., Bergin, M., Dibb, J., Lefer, B., Domine, F., Carman, T., Carmagnola, C., Dumont, M., Courville, Z., Schaaf, C., and Wang, Z.: Comparing MODIS daily snow albedo to spectral albedo field measurements in Central Greenland, Remote Sens. Environ., 140, 118-129, 2014.

Yao, X., Yao, X., Jia, W., Tian, Y., Ni, J., Cao, W., and Zhu, Y.: Comparison and intercalibration of vegetation indices from different sensors for monitoring above-ground plant nitrogen uptake in winter wheat, Sensors, 13, 3109-3130, 2013. 